\begin{tabular}{c|c|c}
\hline ISSN 2525-4812 (versão online) & Revista Terceira \\
$\begin{array}{c}\text { ISSN 2238-7641 (versão impressa) } \\
\text { http://www.revistaterceiramargem.com/ } \\
\text { index.php/terceiramargem/index }\end{array}$ & $\begin{array}{c}\text { Recebido em: 19/6/2019 } \\
\text { Aprovado em: } 30 / 2 / 2020\end{array}$ & $\begin{array}{c}\text { Revisaço } \\
\text { Margem Amazônia }\end{array}$ \\
\hline
\end{tabular}

Como citar o artigo:

DUARTE, F. R; FRAXE, T. J, P; NOGUEIRA, A. R. B. A geograficidade e percepção ambiental de estudantes, moradores da várzea do Rio Solimões produção orgânica na feira agroufam de Manaus, AM. Revista Terceira Margem Amazônia, v. 6, n.15, p. 74-89, 2020. Doi: http://dx.doi.org/10.36882/2525-4812.2020v6i15p74-89.

\title{
A GEOGRAFICIDADE E PERCEPÇÃO AMBIENTAL DE ESTUDANTES, MORADORES DA VÁRZEA DO RIO SOLIMÕES
}

\author{
Fabíola Rocha Duarte ${ }^{1}$ \\ Therezinha de Jesus Pinto Fraxe ${ }^{2}$ \\ Amélia Regina Batista Nogueira ${ }^{3}$
}

\begin{abstract}
Resumo: A relação homem-natureza se configura no espaço geográfico, e se constitui a partir de sua intersubjetividade que se desenvolve, por meio das experiências íntimas, com o lugar. Nesse contexto, o objetivo deste estudo foi compreender a geograficidade e a percepção ambiental, construída pelos estudantes da zona rural, moradores das áreas de várzea (planície de inundação), de uma escola da rede pública de ensino, no Município de Iranduba, ao longo do percurso de sua casa até a escola. Buscamos no método fenomenológico o apoio e o auxílio necessário para compreender a relação do homem com a percepção, o espaço, o mundo e o lugar. Os dados foram coletados a partir da confecção de desenhos de mapas mentais em sala de aula. Os mapas mostraram que o foco da percepção ambiental, presente nos alunos, demostram que eles conhecem mais que o caminho que os levam a escola, eles percebem e se sentem parte dessa relação que se entrelaçam entre eles, a escola e o lugar.
\end{abstract}

Palavras-chave: Percepção Ambiental; Aluno; Mapas Mentais, Iranduba.

\section{GEOGRAFICITY AND ENVIRONMENTAL PERCEPTION OF STUDENTS, RESIDENTS OF THE VARZEA DO RIO SOLIMÕES}

\begin{abstract}
The relation man-nature is configured in the geographical space, and is constituted from its intersubjectivity that develops, through the intimate experiences, with the place. In this context, the objective of this study was to understand the

\footnotetext{
${ }^{1}$ Mestra em Ciências do Ambiente e Sustentabilidade na Amazônia pela Universidade Federal do Amazonas- (UFAM) Professora Seduc- Amazonas. E-mail: yezafabiola@gmail.com

${ }^{2}$ Doutora em Sociologia pela Universidade Federal do Ceará (UFC). Professora Associada da Universidade Federal do Amazonas (UFAM). Coordenadora do Núcleo de Socioeconomia. E-mail: tecafraxe@uol.com.br

${ }^{3}$ Doutora em Geografia pela Universidade de São Paulo (USP). Professora do Programa de Pós-Graduação em Geografia da UFAM ab.nogueira@uol.com.br
} 


\section{Solimões}

geography and the environmental perception, constructed by the students of the rural area, inhabitants of the floodplain areas (floodplain), of a public school in the municipality of Iranduba, along from your home to school. We seek in the phenomenological method the support and assistance necessary to understand man's relation to perception, space, world and place. The data were collected from the preparation of mental map drawings in the classroom. The maps showed that the focus of environmental perception, present in students, shows that they know more than the path that leads them to school, they perceive and feel part of that relationship that intertwines between them, school and place.

Keywords: Environmental Perception; Student; Mental Maps, Iranduba

\section{INTRODUÇÃO}

O espaço e o lugar são inerentes ao homem, ele conhece o espaço indiferenciado, e por intermédio da experiência formada pelo sentimento, e o pensamento adquirido com o tempo, o transforma em lugar. O espaço enquanto desconhecido, transmite sensação de liberdade, de insegurança, medo e angústia, por outro lado à medida que conhecemos o espaço, damos a ele, significado, simbologia e valor, tornando-se lugar. Em outras palavras o lugar é onde o homem constrói suas relações sociais e a vivência, e a partir do seu corpo relaciona à cultura e a história construindo uma geograficidade entre homens e seus lugares.

$\mathrm{Na}$ concepção do lugar, o espaço tem significado temporal ao nível das experiências pessoais diárias, as próprias expressões exibem a íntima ligação entre pessoa, espaço e tempo. "Eu estou aqui (ou nós estamos) aqui; aqui é agora, você (ou eles) estão lá; lá é então, e diz respeito a um tempo tanto pode ser passado como futuro; o que aconteceu então? O então é o futuro" (TUAN, 2013 pp. 156-157). Dessa forma tanto o espaço como o tempo são orientados pelo eu pensante ativo, tornando-se consciente e colaboram na construção dos objetivos. Por outro lado, as experiências que servem para a determinação temporal dos acontecimentos são modificadas pelos habitus sociais dos indivíduos, e segue seu curso independente dos movimentos físicos (ELIAS, 1998).

O resultado dessa interação do homem com a terra seria a geograficidade do homem como modo de sua realidade e de seu destino. A geograficidade se refere a essa convivência obrigatória entre a terra e o homem em que se realiza a existência humana. Ela se refere, também, a um espaço material, uma matéria da qual não podemos nos destacar (DARDEL, 2011). O espaço enquanto objeto desconhecido é visto como inseguro, amplo e não possui valor de apropriação ou significado simbólico para o indivíduo. A partir das experiências vividas com profundidade, o sujeito desenvolve uma relação de afetividade ou pertencimento com o lugar. Em outras palavras, o lugar se 
A geograficidade e percepção ambiental de estudantes, moradores da várzea do Rio Solimões

constitui por meio da experiência adquirida com o tempo e intermediada pela distância que possibilita ao homem a noção do que está perto ou longe, e isso é que vai atribuir valor ao lugar (Tuan, 2013).

Nesse contexto, a presente pesquisa procurou compreender geograficidade e a percepção ambiental, dos alunos a partir do conhecimento agregado das experiências íntimas de cada um com o seu lugar, construído e vivido, ou melhor, como os lugares íntimos onde se encontra sentimento, onde as necessidades humanas são asseguradas e necessitam da vivência para se constituir.

\section{METODOLOGIA}

\section{Área de Estudo}

O lugar escolhido como foco em nossa pesquisa foi a Escola Estadual Isaías Vasconcelos, no Município do Iranduba /AM, que está localizada na sede do Município. Distante $36 \mathrm{~km}$, de Manaus. A escolha da área de estudo deve-se ao fato de a Escola ser a primeira unidade de ensino inaugurada no município de Iranduba, no ano de 1969. Sua implantação iniciou na várzea do Rio Solimões permanecendo nesse local, por quase dez anos. Em 1978, por força de um evento climático extremo, a escola se desloca para a terra firme onde permanece até os dias atuais (CONCEIÇÃO, 2009).

Figura 1 - Localização da Escola Estadual Isaías Vasconcelos, no município de Iranduba, AM.

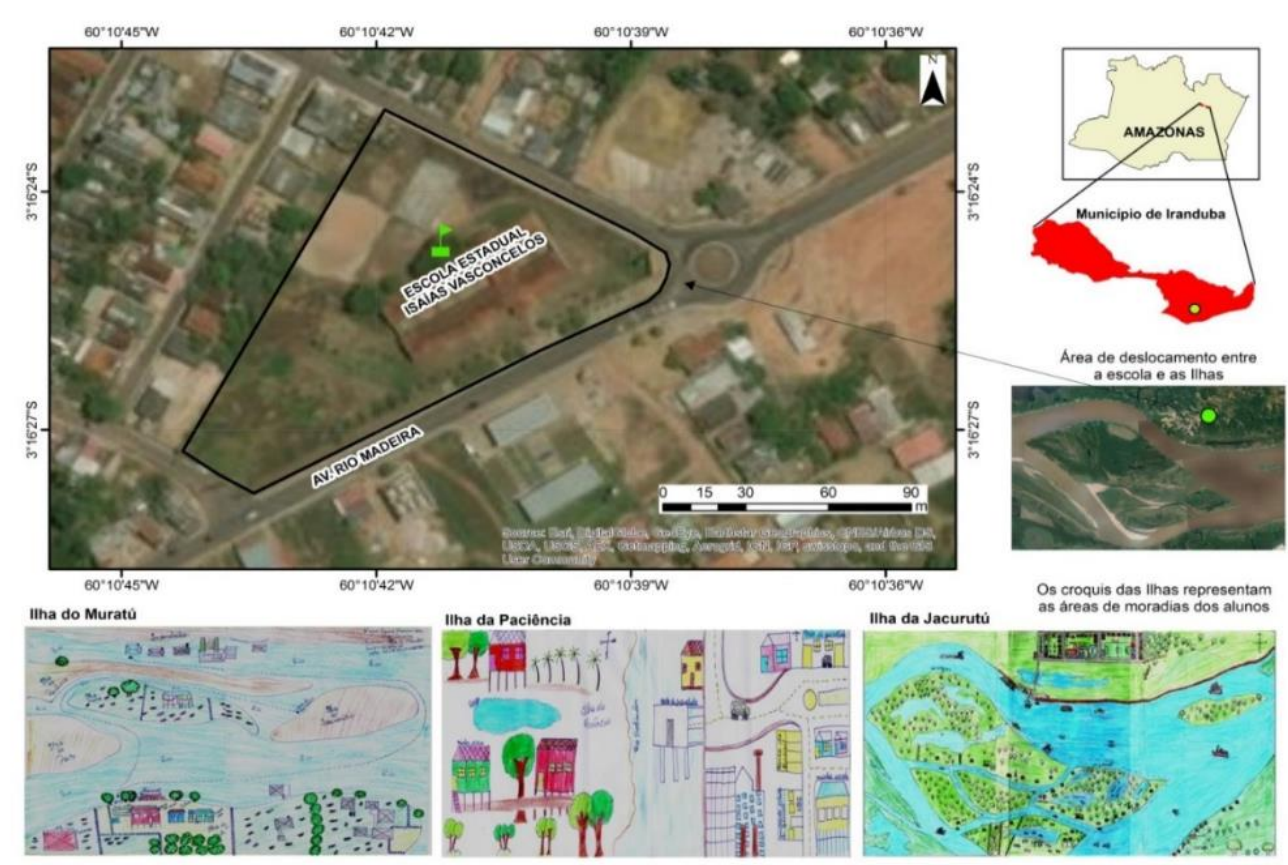


A peculiar história geográfica da Escola Estadual Isaías Vasconcelos, em vários momentos se confunde com a própria história do município e, passados 47 anos, a escola, continua no mesmo lugar para onde foi transferida, quando retirada da várzea do Solimões, na rua rio madeira, no município de Iranduba. Atualmente tende um total de 1.200 (Mil e duzentos) - alunos matriculados, nos horários matutino, vespertino e noturno, respectivamente os três turnos em que a escola funciona. Os alunos são moradores das várzeas do Rio Solimões, Rio Negro e da terra firme (sede e estrada), existindo ainda os que residem no Município de Manaus.

\section{METODOLOGIA}

A presente pesquisa se caracteriza como um estudo exploratório e descritivo de abordagem qualitativa, que segundo Minayo (2009), lida com o universo dos significados, dos motivos, das aspirações, das crenças, dos valores e das atitudes, ou seja, com os fenômenos humanos. As pesquisas exploratórias são desenvolvidas em áreas em que o objeto pesquisado é pouco explorado, tornando difícil a formulação de hipóteses. São aplicadas ainda com "o objetivo de proporcionar, tipo aproximativo acerca de determinado fato" (Gil, 2008). Por isso "buscam levantar informações sobre um determinado objeto, delimitando, assim um campo de trabalho, mapeando as condições de manifestação desse objeto" (Severino, 2007).

Nesta pesquisa buscamos no método fenomenológico o apoio e auxílio necessário para compreender a relação do homem com a percepção, o espaço, o mundo e lugar. Visto que, "o objeto de conhecimento para a fenomenologia não é o sujeito nem o mundo, mas o mundo enquanto é vivido pelo sujeito" (Gil, 2008, p.14). A pesquisa fenomenológica parte do cotidiano, da compreensão do mundo e do viver das pessoas (ibidem, 2008).

Com a intenção de conhecer a percepção ambiental dos estudantes que são oriundos de lugares distintos da várzea, contamos com o auxílio do mapa mental, pois, “as imagens podem diferenciar não só pela escala de área envolvida, mas ainda pelo ponto de vista, hora do dia ou estação do ano" (LYNCH, 1999, p. 97). E “o desenho de mapas é a evidências incontestável do poder de conceituar as relações espaciais" (TUAN, 2013, p. 100). Assim, “os mapas mentais são representações constituídas a partir das percepções dos lugares vividos e diferenciados" (NOGUEIRA, 2014, p. 103). Visto que "o observador procura ajustar a sua imagem a mudanças seculares na realidade a sua volta" (LYNCH, 1999, p. 98). 


\section{RESULTADOS E DISCUSSÃO}

A palavra percepção tem origem no latim perception, e recebe nos dicionários algumas definições como: estímulo, imagem e intuição. Para Merleau-Ponty (1999, p. 10) “A percepção não consiste em uma ciência do mundo, nem mesmo um ato, uma tomada de posição deliberada; ela é o fundo sobre o qual todos os atos se destacam e ela é pressuposta por eles".

A compreensão do mundo e da sociedade é feita por meio dos sentidos: a visão é crucial para situar os objetos e os seres no espaço e apreender os movimentos; a audição dá uma dimensão sonora ao meio, suplementa (imperfeitamente) a visão para apreender a extensão e colorir a vida de momentos, de emoção, de medo ou de pânico; o odor ensina sobre as matérias e junta-se ao gosto para transformar o beber e o comer em prazeres (CLAVAL, 2017, p.81).

Nos estudos de percepção, a noção de sensação é fundamental. “A sensação não é nem um estado ou uma qualidade, nem a consciência de um estado ou de uma qualidade” (NÓBREGA, 2008, p. 02). As sensações são concebidas pelos movimentos: "A cor, antes de ser vista, anuncia-se então pela experiência de certa atitude de corpo que só convém a ela e com determinada precisão."1

Para Merleau-Ponty (1994), a percepção está relacionada à atitude corpórea. “é no meu corpo que compreendo o outro, assim, como é por meu corpo que percebo as coisas" (MERLEAU-PONTY, 1994, p. 253). Assim sendo, temos o seguinte: “o corpo próprio está no mundo assim como o coração; ele mantém o espetáculo visível continuamente em vida, anima-o e alimenta-o interiormente, forma com ele um sistema." ${ }^{2}$ Ou melhor, a identidade das coisas, por meio da experiência perceptiva é apenas um outro aspecto da identidade do próprio corpo no decorrer dos movimentos de exploração.

O que reúne as "sensações táteis" de minha mão e as liga às percepções visuais
da mesma mão, assim como às percepções dos outros segmentos do corpo, é
um certo estilo dos gestos de minha mão, que implica um certo estilo de
movimentos de meus dedos e contribui, por outro lado, para uma certa
configuração de meu corpo (MERLAEU-PONTY, 1994, p. 208).

De todos os sentidos usuais, as pessoas dependem mais racionalmente da visão, para projetar o mundo. Por meio da visão o mundo com maior abrangência surge carregado de informações essencialmente detalhadas, mais até que os outros sistemas sensórios como paladar, olfato, audição e tato. Por meio da visão constroem as imagens

\footnotetext{
${ }^{1}$ MERLEAU-PONTY, Maurice. Fenomenologia da percepção. São Paulo: Martins Fontes, 1994.

${ }^{2}$ Ibid., p. 273.
} 
do espaço. "A imagem como entendimento do ambiente é utilizada desde a pré-história, com o aparecimento da linguagem simbólica, quando o homem desenhou gravuras na pedra com as cenas do seu dia-a-dia e de sua trajetória” (LIMA e KOZEL, 2009). Para Lynch (1999), a imagem permite que as pessoas se desloquem facilmente e depressa ajuda a encontrar a casa de um amigo, uma loja, um guarda. Mas sem dúvida o meio ambiente organizado possibilita ir, além disto, ele serve como estrutura de referência, um organizador de atividade, de valores ou conhecimento. $\mathrm{O}$ autor reafirma ainda, que a imagem do meio ambiente é uma fonte útil para o crescimento do indivíduo como mostra abaixo:

\begin{abstract}
A imagem de um bom meio ambiente dá a quem possui um sentimento importante de segurança emocional. Pode estabelecer uma relação harmoniosa entre si e o mundo exterior. Isto é o inverso do medo que deriva da desorientação; significa que o doce sentido do lar é mais forte quando o lar é não só familiar, mas também distintivo (LYNCH, 1999, pp. 14- 15).
\end{abstract}

Os mapas mentais são imagens produzidas por meio das observações sensíveis da experiência humana com o lugar e não se alicerçam em informações precisas e préestabelecidas, pelo fato da razão objetiva se remeter a existência humana independente de categorias de identidade (LIMA E KOZEL, 2009).

Para Tuan (2012), a cultura esboça um papel importante na percepção e valores ambientais de cada pessoa. Pois, à medida que a sociedade e a cultura se modificam com o passar do tempo elas podem mudar suas convicções em relação ao meio ambiente. $\mathrm{O}$ autor destaca que o meio ambiente natural e a percepção de mundo estão interligados a percepção do mundo e se não tem origem em uma cultura desconhecida é constituída por elementos do ambiente social e físico de um povo.

O conceito de cultura é próprio à reflexão das ciências sociais. Ela é necessária de certa forma para refletir a unidade da humanidade na diversidade além das terminações biológica. Ela parece prover à resposta mais próxima a questão das diferenças entre os povos. O ser humano é fundamentalmente um ser de cultura. A cultura possibilita aos seres humanos não somente adequar-se ao seu meio ambiente como também adaptar-se esse meio ao próprio homem as suas necessidades e seus projetos, em resumo, a cultura torna viável a transformação da natureza (CUCHE, 1999).

Alguns autores como Bourdier (1989) e Elias (1994) apresentam a cultura como habitus que seria aquilo que está profundamente enraizado no seu interior que permite aos indivíduos se orientarem em seu espaço social e adotarem práticas que estão de acordo com sua vinculação social (CUCHE, 1999). Ele torna viável para os indivíduos a 

Solimões

configuração de meios de antecipação que são guiadas de maneira inconsciente. $O$ conceito de habitus não foi criador por Bourdier, porém a concepção que o autor apresenta para habitus tornou-se mais sistêmicas. Para o autor, os habitus são:

[...] sistemas de disposições duráveis e transponíveis, estruturas, estruturadas predispostas a funcionar como estruturas estruturantes, isto é a funcionar como princípios geradores e organizadores de práticas e de representações que podem ser objetivamente adaptadas a seu objetivo sem supor que se tenham em mira conscientemente estes fins e o controle das operações necessárias para obtê-los (1980, apud CUCHE, 1999, p. 171).

Na paisagem amazônica encontramos dois ambientes, o ecossistema de terra firme e o ecossistema de várzea. Ambos são carregados de simbologia por aqueles que os vivenciam. Estás paisagens influenciam diretamente a identidade cultural, bem como a percepção que o estudante morador possui, seja, nas áreas de várzeas do rio Solimões ou da terra firme. Nas áreas alagadas, a relação do estudante ribeirinho com a água que constitui seu cotidiano se torna de vital importância para a compreensão da relaçãohomem natureza que constitui sua geograficidade.

Durante os cinco ou seis meses do ano - período das cheias, os estudantes ribeirinhos moradores das várzeas, das Ilhas do Jacurutu, Muratu, Paciência e Costa do Iranduba, no rio Solimões, coabitam com a água. Nesse período a água está por todos os lugares, nas residências, nas plantações e no comercio. $\mathrm{O}$ cotidiano de cada aluno ribeirinho está ligado diretamente a água. Os alunos moradores das várzeas, na maioria das vezes só saem de suas casas, nesse período de enchente, para irem à escola que está localizada na terra firme. Para isso, fazem uso dos transportes escolar que consiste em primeiro pegar o barco na porta de casa e atravessar o rio até a outra margem para pegar o ônibus. Esse trajeto é feito diariamente pelos estudantes que conhecem cada trajeto.

Fraxe (2004), de forma muito clara destaca o valor de uma imagem para os ribeirinhos, diz ela:

O valor de uma imagem para os caboclos-ribeirinhos é percebido pela extensão que eles têm de sua percepção imaginária daquilo que os cerca, como por exemplo: o rio, a água, o chapéu de folha, o vestuário, a terra molhada, o caminho na água, quando a enchente que chega, a cheia, a casa submersa, o alimento que vem d'água. ${ }^{3}$

${ }^{3}$ FRAXE, Therezinha J. P. Cultura cabocla-ribeirinha: mitos lendas e transculturalidade. São Paulo: Annablume, 2004, p. 296. 
Os caminhos percorridos mudam de configuração e se reconstroem a cada movimento do rio, pois como eles salientam em seus diálogos nos mapas mentais, suas referências mudam de acordo com o movimento de subida e descida dos rios, e da própria chuva, ilhas, casas e árvores aparecem e desaparecem de acordo com a nova paisagem que se forma. Este saber é fruto da experiência de cada um com o lugar. Dessa forma, neste trabalho os Mapas Mentais dos estudantes, foram apresentados paralelos aos seus relatos. Pois ao representar o que cada lugar tinha no caminho percorrido a explicação da paisagem que estavam vendo e que seria colocado era para eles fundamental. Com uma linguagem simples e de adolescentes que são, os desenhos simples e bem detalhados dos estudantes nos mostraram como é o caminho que percorrem nas várzeas da zona rural do Iranduba, de suas casas até a sua escola. Como mostra o mapa (01) a seguir.

Mapa 1: Percurso casa - escola, Iranduba. Período da vazante e seca. Costa do Iranduba (Rio Solimões). (A) início do trajeto; (B) final do trajeto. Vazante e seca.

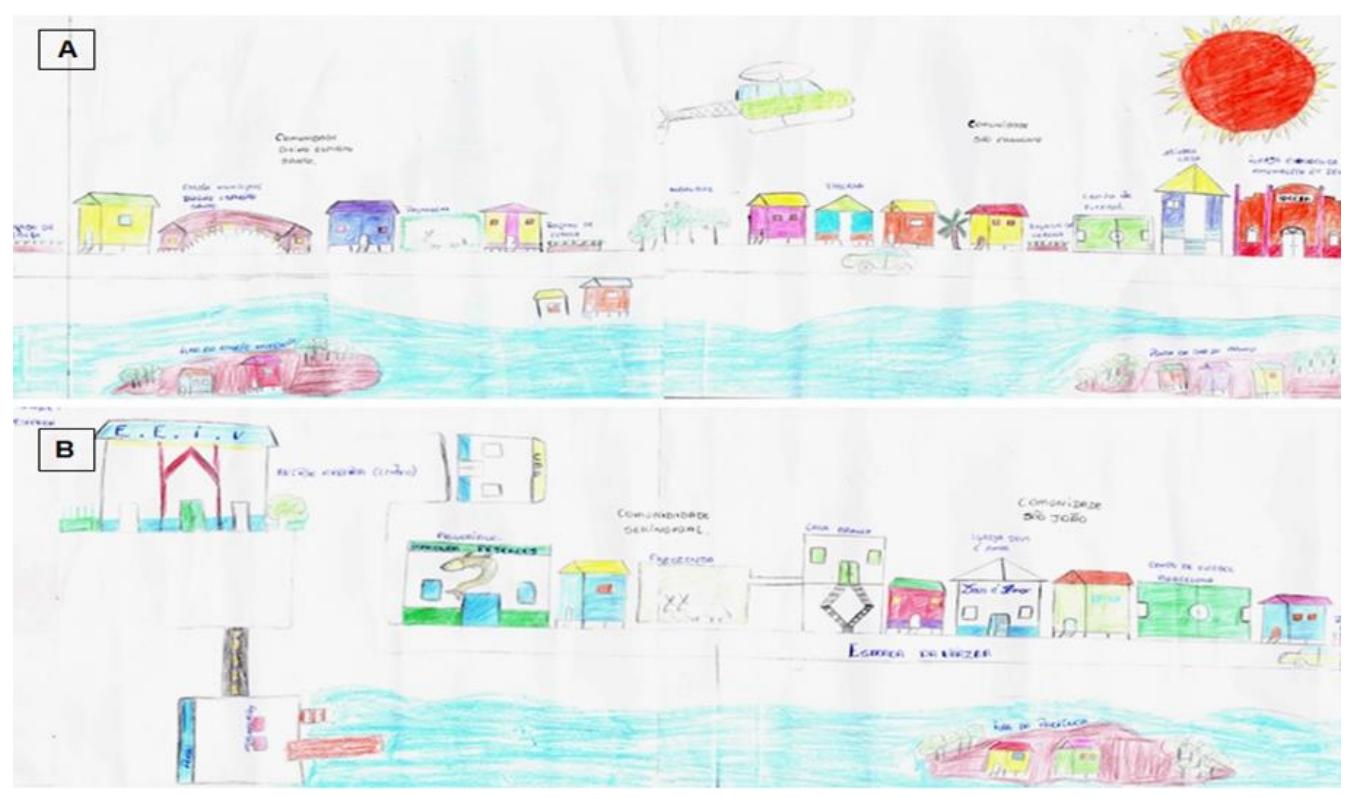

Fonte: Estudante F.R.S. (Feminino), 16 Anos, $1^{\circ}$ ano (vespertino), 2018

O mapa, que representa o lugar onde a estudante mora e que se encontra no período de vazante e seca. Verifica-se que a aluna, ressalta todos os elementos considerados mais significativo, apresentando cada um pelos seus respectivos nomes como: a religiosidade representada pela igreja, o carro transitando na estrada, o campo de futebol, usado na comunidade onde mora para o lazer, o frigorifico, as casas, entre outros elementos que compõem o lugar em que mora, demonstrando afinidade com esse ambiente, e que contribuem para sua localização e orientação. Essa representação tornase significativa para a percepção do lugar como espaço vivido. Mostrando tanto sua 
afetividade como subjetividade pelo lugar. E estes são elementos importantes na construção de mapas mentais.

Estudante R. F, S. (2018):

[...] moro na estrada da várzea, a costa do Iranduba. [...]. O que eu mais gosto na escola é a educação de qualidade, não que onde eu moro não seja, é que eu gosto daqui da escola. [..] em casa o que eu mais gosto são as frutas, gosto de ficar lá no quintal apanhando fruta, gosto do campo que tem lá do lado de casa porque eu gosto de jogar futebol [...]. No caminho quando eu venho gosto de ficar olhando a paisagem porque é muito bonito, ficar olhando pro rio, pras árvores e as fazendas que tem [...] quando eu venho pra escola o que dificulta é quando chove a estrada fica bem ruim e no caminho às vezes dá medo porque tem muito bicho, assim os búfalos atravessando a rua, porque eles vem em direção e a moto [...] de lá da minha casa até aqui quando tá seco dá entorno de vinte e cinco minutos porque pega só o transporte, mas quando tá alagado dá entorno de uma hora porque a gente pega o barco e depois o transporte pra subir pra cá pra escola [...] Aqui na escola eu tenho medo de ser assaltada porque aqui tem esse é o perigo só isso mesmo.

Quando perguntada sobre o que mais gosta de fazer, onde reside a aluna moradora várzea relata o que "em casa o que eu mais gosto são as frutas, gosto de ficar lá no quintal apanhando fruta, gosto do campo que tem lá, do lado de casa porque eu gosto de jogar futebol" Esse relato mostra que o lugar onde habita é carregado de afetividade e íntimo os lugares "íntimos são lugares onde encontramos carinho, onde nossas necessidades fundamentais são consideradas e merecem atenção sem espalhafato" (TUAN, 2013, p. 168). Com efeito "podem ficar gravado no mais profundo da memória e, cada vez que são lembrados, produzem intensa satisfação [..]” (TUAN, 2013, p. 172). Ou seja, o lugar é dado a partir da experiência de cada um.

No mapa, o desenho mostra que a aluna representou além, dos elementos já apresentados anteriormente, as lanchas canoas e barcos, não que eles não façam parte da sua vida ribeirinha mas porque nesse período, o uso da lancha para chegar a escola se faz fundamental, pois o percurso acaba ficando mais longo nesse período como ela expõem “[...] de lá da minha casa até aqui quando tá seco dá entorno de vinte e cinco minutos porque pega só o transporte, mas quando tá alagado dá entorno de uma hora porque a gente pega o barco e depois o transporte pra subir pra cá, pra escola [...]”. O barco é um meio de transporte de extrema importância na vida dos ribeirinhos, pois é por meio dele que ele se desloca até a cidade.

A escola, está desenhada em tamanho maior que os demais elementos. A aluna demonstra uma ter relação prazerosa e de confiança com a escola, e fico explicito na sua fala quando afirma que "o que eu mais gosto na escola é a educação de qualidade, não que onde eu moro não seja, e que eu gosto daqui da escola." Cabe ressaltar que a escola 
A geograficidade e percepção ambiental de estudantes, moradores da várzea do Rio Solimões

é o lugar onde a aluna se encontra com os colegas que estudam lá, e que moram na terra firme. Dessa forma a escola é um "lugar contém uma multiplicidade de relações, discerne um isolar, ao mesmo tempo em que se apresenta como realidade sensível correspondendo a um uso, a uma prática social vivida." (CARLOS, 2007, p.22).

O mapa a seguir mostra o caminho que o aluno morador da Ilha do Jacurutu, situada no Rio Solimões faz até a escola mapa (02).

Mapa 2: Percurso casa - escola, Iranduba - Ilha do Jacurutu (Rio Solimões).

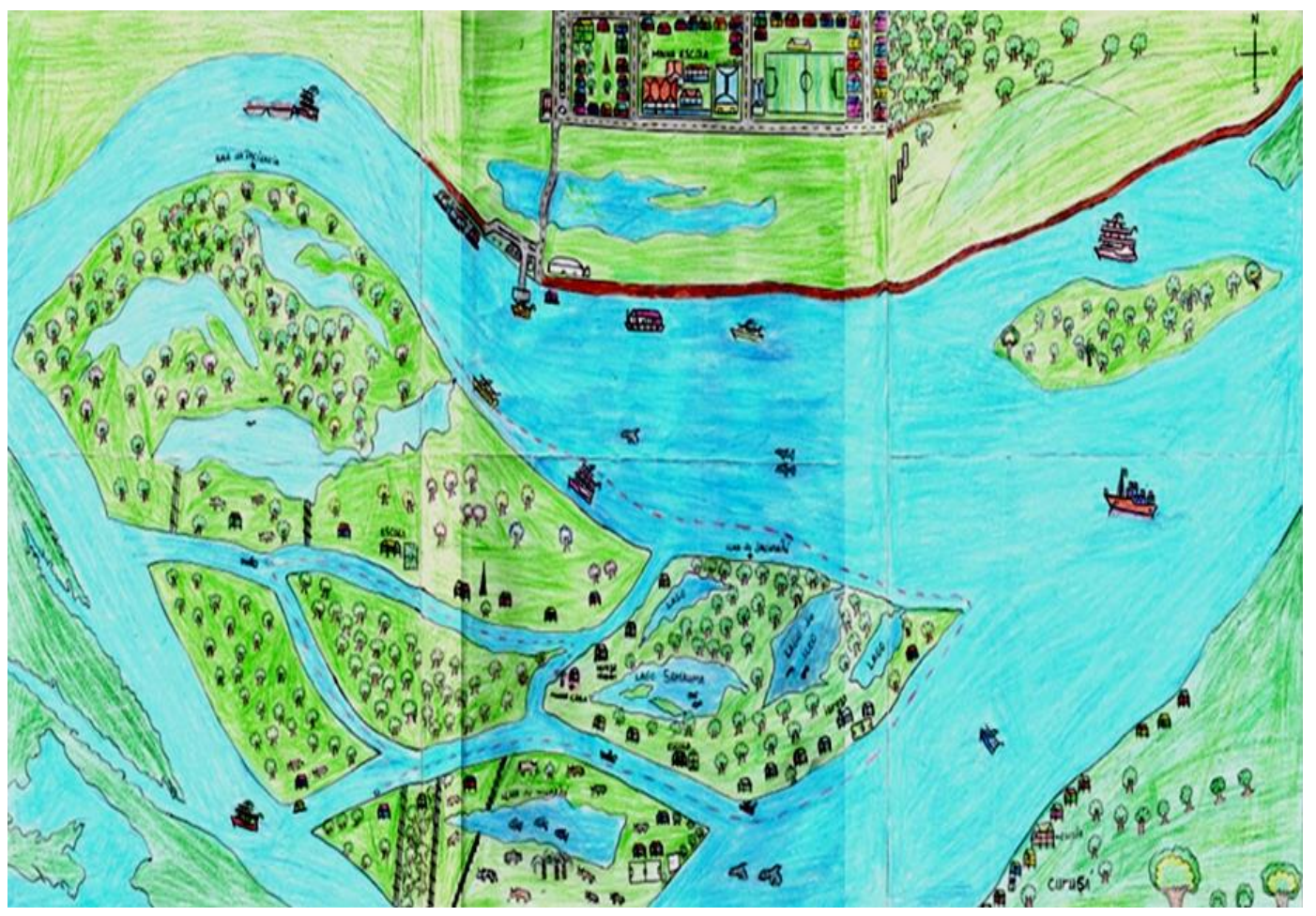

Fonte: Estudante C. P. B. (Masculino), 17 Anos, $1^{\circ}$ ano (vespertino), 2018.

O mapa desenhado por um estudante, morador da ilha do Jacurutu, na área de várzea, destaca - se na parte central as ilhas que se sobressaem, durante o período de vazante, que ficam próximo a sua casa. A riqueza de detalhes, como os navios, as casas de palafitas, o boto, as árvores, o gado, criado na várzea e os lagos com os peixes, chamam atenção. Isso ocorre devido à experiência com lugar vivido. Pois "o lugar, não é somente aquilo que eu penso, mas aquilo que eu vivo" (MERLEAU- PONTY, 1999, p. 14). Entre a casa e a escola, encontra-se o Rio Solimões - caminho até a escola, nele os barcos e canoas, estão em evidência, e em movimento no ir e vir do banzeiro, exibindo as relações sócio espaciais, e mostrando que "os elementos moveis de um lugar, essencialmente as pessoas e as suas atividades, são tão importantes como as partes físicas”. (LYNCH, 1999, p.10). Como mostra o relato do aluno. 


\title{
A geograficidade e percepção ambiental de estudantes, moradores da várzea do Rio Solimões
}

Estudante C. P. B. (2018):

\begin{abstract}
[...] eu desenhei a natureza da ilha do Jacurutu [...]. Porque eu queria destacar um pouco os pontos de referências. As casas onde poderiam servir de ponto de referência até chegar a minha. Fiz a linha imaginaria de onde seria a minha trajetória até eu chegar na minha escola [...] e é isso que procurei destacar a natureza. O que eu mais gosto no caminho é a natureza mesmo, olhar pra natureza, ver os animais e a floresta. Na minha casa o que eu mais gosto é quando tá de tarde, a pessoa pode ir pra beira do barranco, a gente ver a torre do Iranduba, ver o Iranduba e ver o pôr do sol. O mais perigoso quando eu venho pra escola é a travesseia, tanto na cheia quanto na seca, tanto na época que tem ladrão, quanto dia de chuva que banzeira muito, existe época, as vezes que tem ladrão que rouba motor [...] aí pode representar perigo pra gente nessa travessia aí de noite, que é a hora que a gente chega da escola em casa. [...]. É um pouco difícil sair de casa pra chegar aqui, ainda mais na seca porque eu tenho que andar pra cá [...] ando uns trinta minutos, até a margem pra pegar a lancha, quando tá cheio não [...] porque a lancha para na porta. [...]. Na escola o que eu mais gosto é da biblioteca e da aula de educação física [...] o ensino aqui acho que é melhor do que o de lá [...] lá tem escola só que o ensino não é que nem o daqui. Se pudesse eu moraria aqui perto da escola, tanto por causa de meios, de sonhos que a gente tem, de oportunidades seria melhor. Na escola tenho medo dos roubos que andam acontecendo aqui dentro [...] e se eu pudesse melhoraria a segurança aqui da escola. Na hora que eu volto pra casa, gosto de ver os botos, que é comum a gente ver, tanto na cheia quanto na seca, entre as ilhas, eu gosto de ver, acho legal, tem comunhão com a natureza [...]. Eu acho importante a gente continuar preservando a natureza nesse local, pra continuar, assim, da forma que Deus criou.
\end{abstract}

No relato do estudante morador da várzea um ponto importante é quando destaca que: "gosto de ver os botos que é comum a gente ver, tanto na cheia quanto na seca, entre as ilhas, eu gosto de ver, acho legal". O boto é uma figura presente no cotidiano ribeirinho e, vale ressaltar que na Amazônia o boto é muito mais que um simples mamífero, ele é um "ser encantado da metamorfose, por excelência, expansão de uma espécie de êxtase dionisíaco [...] o D. Juan das águas, sedutor de moças donzelas e mulheres casadas” (FRAXE, 2010, p. 326). O próximo mapa (03) mostra o caminho da escola que a estudante realiza para chegar à escola.

Mapa 3: Percurso casa - escola, Iranduba - Período da enchente e cheia, Ilha do Muratu (Rio Solimões).

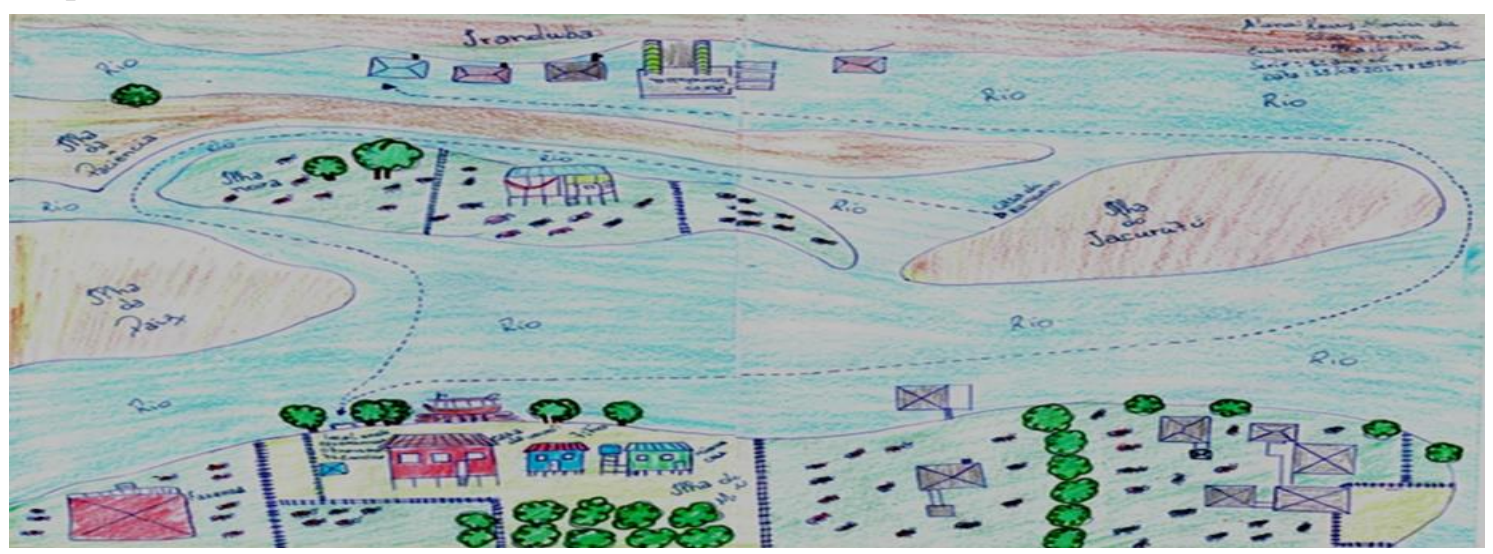


Fonte: Estudante K. M. S. P, (Feminino), 14 Anos, $1^{\text {o }}$ ano (vespertino), 2018.

Quando indagada sobre o qual o seu lugar preferido, o relato que ela faz da sua vivência com o lugar chega a ser impressionante, principalmente quando ela diz "lá não tem um lugar preferido, porque praticamente tudo faz parte da nossa vida né, assim, o cotidiano, então, tudo faz parte né, não tem o que não gostar, não tem [...].”. a facilidade em afirmar que não existe um único lugar preferido, mostra sua intimidade com o lugar isso se ocorre porque "as experiências intimas com o lugar não são difíceis de expressa"(TUAN, 2013, p. 167), e fica mais visível quando ela continua dizendo que "gosto também do campo e da casa da minha vó Pizorina, onde a gente brinca de bola, eu também gosto das praias porque dá pra tomar banho, mas, tem que ter cuidado com as arraias, mais na seca, mas pra quem já é acostumado, lá, não tem perigo não porque já conhece $[\ldots]$.

Estudante K. M. S. P. (2018):

\begin{abstract}
Eu moro na Ilha do Muratu [...] lá não tem um lugar preferido, porque praticamente tudo faz parte da nossa vida né, assim, o cotidiano, então, tudo faz parte né, não tem o que não gostar, não tem [...]. Gosto também do campo e da casa da minha vó Pizorina, onde a gente brinca de bola, eu também gosto das praias porque dá pra tomar banho, mas, tem que ter cuidado com as arraias, mais na seca, mas pra quem já é acostumado, lá, não tem perigo não porque já conhece [...]. Quando seca eu não gosto muito é pra vir pra escola, por causa da praia porque fica longe pra gente, e tem que andar muito no sol, mais de meia hora, pra gente chegar até o porto [...] quando seca o porto fica na ponta do Jacurutu então a gente tem que andar na praia, mas, quando enche a lancha pega a gente na porta de casa mesmo [...]. Na escola eu gosto da biblioteca e dos amigos que eu fiz e só [...]. Eu gosto de morar na várzea. [...] eu não me acostumo na cidade então, eu preferia ficar na várzea mesmo. No caminho quando eu venho pra escola o que é mais perigo é quando chove mesmo porque fica banzeirando e aí dá um pouco de medo, principalmente à noite na hora que a gente chega da escola, porque nós somos os últimos a ficar. Agora aqui na escola é diferente né porque aqui já é cidade né, tem mais perigo, por conta de assalto, essas coisas que a gente ver muito né, assalto em escola.
\end{abstract}

No mapa A, onde está casa da aluna, localizada na Ilha do Muratu, destaca-se na parte inferior esquerda. A riqueza dos ícones representando as casas uma ao lado da outra e o barco atracado praticamente na porta, mostra todo o cuidado e atenção aos mínimos elementos do meio ambiente. Lynch (1999) mostra que as imagens do meio ambiente resultam de um processo bilateral entre o observador e o meio. "O meio ambiente sugere distinções e relações e o indivíduo de acordo com seus critérios dota de sentido aquilo que ele vê" (LYNCH, 1999, p. 16). Cada pessoa possui uma identificação com o seu próprio lugar um sentimento de topofilia, único para cada ser.

Essa é a experiência de quem conhece o lugar e com ele mantem uma relação que vai além do perceber é uma relação de vida, de trocas onde "o homem e o rio são os dois 
mais ativos agentes da geografia humana da Amazônia [...] o rio enchendo a vida do homem de motivações psicológicas, o rio imprimindo à sociedade rumos e tendências, criando tipos característicos na vida regional" (TOCANTINS,1973, p.280).

O mapa expressa diversos elementos icônicos marcantes da paisagem que compõem o lugar onde a estudante mora, no período da vazante do rio Solimões. Nele é possível ver todas as ilhas que ficam em frente a município de Iranduba. Podemos notar as relações de trocas como representado na figura do gado, criado no pasto de várzea, no período da seca e levado a maromba quando as águas sobem. Esses gados junto com a plantação de hortaliças são revendidos na cidade. Esse é um tipo de campesinato praticado pelos caboclo -ribeirinhos.

O medo também se faz presente na relação - homem lugar que a estudante vive, como demonstra sua fala "no caminho quando eu venho pra escola o que é mais perigo é quando chove mesmo porque fica banzeirando e aí dá um pouco de medo, principalmente à noite na hora que a gente chega da escola, porque nós somos os últimos a ficar. " $\mathrm{O}$ medo existe na mente [...] e tem origem em circunstância externas que são realmente ameaçadoras" (TUAN, 2005, p. 12).

Conforme o caminho até a escola se desenha a frequência e os pontos de referências diminuem de acordo com a direção e distância da casa do aluno. Isso ocorre pelo fato de que a "situação de um homem pressupõe um espaço onde ele se desloca, um conjunto de relações e de trocas, direções e distâncias que fixam de algum modo o lugar da sua existência" (DARDEL, 2011, p. 147).

A escola aparece representada por um ícone de um simples prédio, isso se deve ao fato da escola não ser vista como um lugar íntimo - mas como um lugar sem história, um não lugar, da qual não tem lembrança e que faz parte do seu cotidiano há pouco tempo, que o lugar quando carregado de subjetividade "é parte essencial de nossa identidade enquanto sujeitos" (SOUZA, 2015, p. 309).

\section{CONSIDERAÇÕES FINAIS}

Procuramos interpretar o lugar de forma que as informações demonstradas nele, pudessem ser compreendidas por quem, não faz parte desse lugar, ou seja, pelos que são de fora. O que resultou em mapas mentais com representações gráficas, dos lugares produzidos com o conhecimento de quem nele mora. Os mapas Mentais mostram a interpretação que cada estudante faz dos lugares, revelam como são concebidos os lugares 
A geograficidade e percepção ambiental de estudantes, moradores da várzea do Rio Solimões

por quem neles habitam. A visão de cada aluno indica um novo caminho, dando diferentes identidades, sejam elas, sócias, ambientais, econômicas, culturais, naturais, entre outras.

Ao interpretar os mapas dos alunos que moram na várzea do rio Solimões, percebemos que eles interagem e mantém com esse ambiente uma relação de forte ligação. Existe um rio que ora está dentro de casa, ora no quintal, há um elo que vai além da compreensão de quem não faz parte desse lugar. O acordar cedo para cuidar da roça que está na frente de casa ou atrás não é só uma obrigação, é para uns uma escolha de vida. Isso ficou constatado no relato que cada estudante fez. Assim, verificou-se que a percepção ambiental, dos estudantes da zona rural, é um instrumento que assegura a importância que o ambiente natural, têm para os sujeitos que vivem uma ligação latente com o rio, com toda a sua simbologia e sentimento de pertença.

\section{REFERÊNCIAS}

CONCEIÇÃO, R. S. A percepção da Degradação ambiental em Iranduba-AM: Uma Análise Integrada. Dissertação. Universidade Federal do Amazonas - Manaus - AM. 2009.

CARLOS, A. F. A. O lugar no/do mundo. São Paulo: FFLCH, 2007.

CLAVAL, P. A geografia cultural. Trad. Luiz Fugazzola Pimenta e Margareth de Castro Afeche Pimenta. 3. Ed. - Florianópolis: Ed da UFSC, 2007.

CUCHE, D. A noção de cultura nas ciências sociais. Trad. Viviane Ribeira. Bauru: EDUSC, 1999.

DARDEL, E. O homem e a terra: natureza da realidade geográfica. Trad. Werther Holzer. São Paulo: Perspectiva, 2005.

ELIAS, N. Sobre o Tempo. Rio: Zahar, 1998.

FRAXE, T. J. P. Cultura cabocla-ribeirinha: mitos, lendas e transculturalidade. São Paulo: Annablume, 2004.

GIL, A. C. Como elaborar projetos de pesquisa. São Paulo: Atlas, 2010.

HALL, S. Identidade cultural na pós modernidade. Trad. Tomaz Tadeu da Silva, Guacira Lopez Louro - 11 ed. - Rio de Janeiro: DP\&A, 2006. 
A geograficidade e percepção ambiental de estudantes, moradores da várzea do Rio Solimões

LIMA, A. M. L; KOZEL, S. Lugar e mapa mental: uma análise possível. Geografia, Londrina, V. 18, n. 1, 2009. Disponível em:

<http://www.uel.br/revistas/uel/index.php/geografia/article/view/2388> Acesso em: 20 de dezembro de 2016.

LYNCH, K. A imagem da cidade. Lisboa - Portugal: Edições 70, 2009.

MERLEAU-PONTY, M. Fenomenologia da Percepção. $3^{a}$ ed. São Paulo: Martins fontes, 1999.

MINAYO, M. C. S. (org.). Pesquisa Social: teoria, método e criatividade. 28 ed. Petrópolis, RJ: Vozes, 2009.

NOGUEIRA, A. R. B. Percepção e representação gráfica: a Geograficidade nos mapas mentais dos comandantes de embarcações no Amazonas. Manaus: Edua, 2014.

NOBREGA, T. P. Corpo, percepção e conhecimento em Merleau-Ponty. In Estudos de Psicologia 2008, 13(2), 141-148. Universidade Federal do Rio Grande do Norte Disponível em: <http://www.scielo.br/epsic> Acesso em 20 de Dezembro de 2017.

SEVERINO, A. J. Metodologia do trabalho científico. 23 ed. São Paulo: Cortez, 2007.

SOUZA, M. 1. D. O espaço fora do lugar: uma suposta filosofia geográfica do espaço e lugar. In: Revista do Departamento de Geografia - USP, Volume 29, p. 305 a 319. 2015. Disponível em:

<http://www.revista.usp.br/rdg/article/download/102127/100548> Acesso em 11 de dezembro 2016.

TOCANTINS, L. O rio comanda a vida: Uma interpretação da Amazônia. Rio de Janeiro: Biblioteca do Exército, 1973.

TUAN, Y. Espaço e lugar: A perspectiva da experiência. Trad. Lívia de Oliveira. Londrina: Eduel, 2013. 